\title{
Direct arylations on water: synthesis of 2,5-disubstituted oxazoles balsoxin and texaline $\dagger \ddagger$
}

\author{
Stephan A. Ohnmacht, ${ }^{a}$ Patrizia Mamone, ${ }^{a}$ Andrew J. Culshaw ${ }^{b}$ and \\ Michael F. Greaney*a \\ Received (in Cambridge, UK) 18th December 2007, Accepted 18th January 2008 \\ First published as an Advance Article on the web 5th February 2008 \\ DOI: $10.1039 / \mathrm{b} 719466 \mathrm{~h}$
}

\begin{abstract}
An efficient two-step palladium catalysed synthesis of 2,5disubstituted oxazoles is reported.
\end{abstract}

The functionalisation of heteroaromatic compounds by transition metal (TM) catalysed $\mathrm{C}-\mathrm{C}$ bond formation complements classic condensation chemistry as a strategy for polyfunctional heteroaromatic synthesis. ${ }^{1}$ Whereas classic heterocyclic synthesis frequently involves the preparation of appropriately substituted acyclic precursors which undergo cyclocondensation as a final step, TM-catalysed cross couplings offer the possibility of taking the parent, commercially available heteroarenes and selectively functionalising the $\mathrm{C}-\mathrm{H}$ bonds around the heteroarene nucleus. The two approaches are illustrated in Scheme 1 for a 2,5-disubstituted azole synthesis. Whilst the condensation route is generally reliable and built upon many years of literature precedent, the preparation of the appropriately substituted precursor $\mathbf{1}$ is necessarily multi-step and the subsequent condensation is usually carried out under forcing conditions. The TM-catalysed approach offers significant advantages of speed and synthetic expediency in comparison, along with the potential for mild $\mathrm{C}-\mathrm{C}$ bond forming reaction conditions.

Importantly, the cross-coupling route enables the introduction of diversity at a late stage, rather than the early stage mandated by the condensation approach, a strategic advantage $^{2}$ in the type of intensive analog synthesis required by contemporary medicinal and agrochemical chemistry.

The TM-catalysed approach becomes even more attractive if direct arylation can be incorporated as a $\mathrm{C}-\mathrm{C}$ bond forming reaction. ${ }^{3}$ Here, the stoichiometric metallation required for classic cross-couplings such as the Suzuki-Miyaura, Stille and Negishi reactions is dispensed with, in favour of direct $\mathrm{C}-\mathrm{H}$ bond functionalisation. ${ }^{4}$ We now report the preparation of assorted 2,5-diaryloxazoles using TM-catalysed chemistry: Negishi coupling at the 2-position using a stoichiometric zincate followed by direct arylation at the 5-position under mild 'on water' conditions. The oxazole heteroarene structure

\footnotetext{
${ }^{a}$ University of Edinburgh, School of Chemistry, Joseph Black Building, King's Buildings, West Mains Rd, Edinburgh, UK EH9 3JJ

${ }^{b}$ Global Discovery Chemistry, Novartis Horsham Research Centre, Wimblehurst Road, Horsham, West Sussex, UK RH12 5 AB

$\dagger$ CCDC 671459. For crystallographic data in CIF or other electronic format see DOI: $10.1039 / \mathrm{b} 719466 \mathrm{~h}$

$\ddagger$ Electronic supplementary information (ESI) available: Experimental procedures and characterization data for all new compounds. See DOI: $10.1039 / \mathrm{b} 719466 \mathrm{~h}$
}

has widespread application in medicinal, agrochemical, natural products and materials chemistry. ${ }^{5}$

Taking commercially available oxazole as our starting point, we functionalised the 2-position using a Negishi crosscoupling protocol developed by Reeder and co-workers. ${ }^{6}$ Following lithiation with $n$-BuLi at $-78{ }^{\circ} \mathrm{C}$, solid $\mathrm{ZnCl}_{2}$ is added to form the zincate, which subsequently undergoes Pdcatalysed coupling with aryl iodides at $60{ }^{\circ} \mathrm{C}$. The procedure proved very effective for the preparation of the four 2-arylated oxazoles 6a-d, 6b having been exemplified in Reeder's work and $\mathbf{6 a}$, c, $\mathbf{d}$ being newly prepared using this method. With these substrates in hand, we turned our attention to the direct arylation of the oxazole 5-position. We have recently developed an effective on water ${ }^{7}$ method for the direct arylation of heteroarenes ${ }^{8}$ high yields of arylated products are produced under far milder conditions than those typically employed in literature heteroarene arylations.

We were pleased to observe that the on water direct arylation is effective across a wide range of aryl iodides (Table 1), with yields being good to excellent for the 2-substituted oxazoles 6a-c. The scope of aryl iodide covers electron rich (entries 5 and 6), electron poor (entries 3, 4, 7 and 9), sterically hindered (entries 2 and 10) as well as aryl iodides which contain additional functional handles for further elaboration such as aryl halide (entries 7 and 8) and acyl (entry 9). The process was poorly effective for pyridyl iodides, ${ }^{9}$ producing very slow reactions with low yields of the oxazoyl pyridines (30-36\%), with homocoupling of the oxazole being the dominant side-reaction. ${ }^{10}$

The average yield across the 30 examples in Table 1 was $85 \%$, illustrating the power of the direct arylation method for the rapid assembly of functionalised heteroarenes. This is the first study of oxazole arylation that examines substrate range;

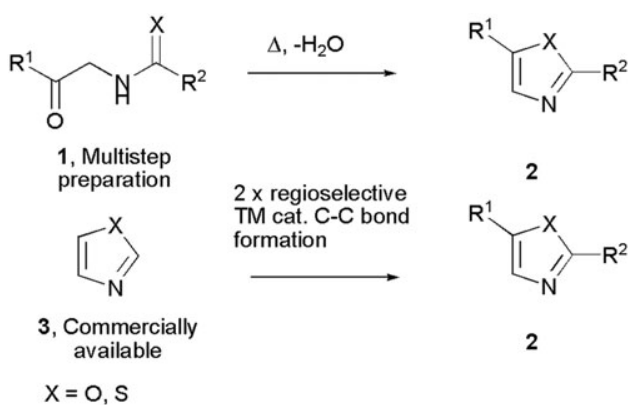

Scheme 1 Heteroarene synthesis via condensation and TM-catalysed methods. 
Table 1

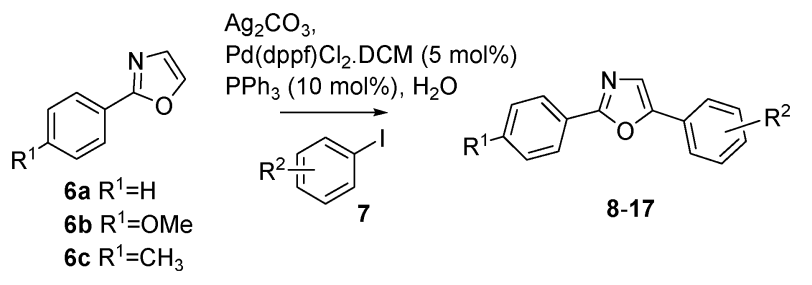

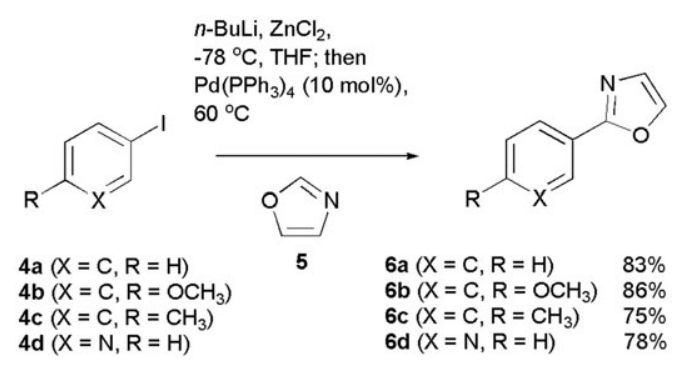

Scheme 2 2-Aryloxazole synthesis via Negishi cross-coupling.
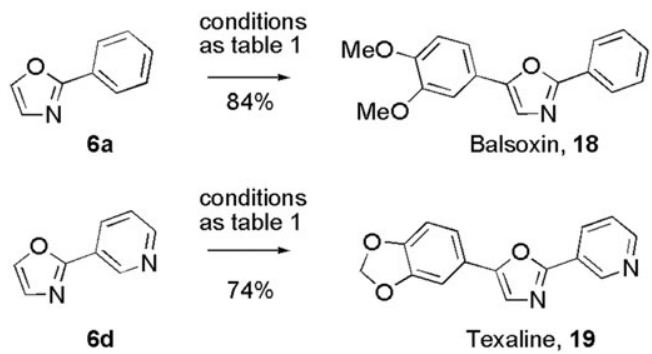

conditions
as table 1

$6 d$

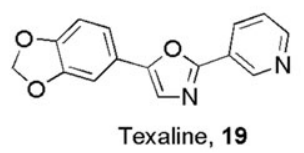

Scheme 3 Synthesis of balsoxin and texaline.

texaline are 2,5-diaryloxazoles isolated from Amyris species of plant in the Caribbean, ${ }^{12,13}$ with texaline reported to have antimycobacterial activity against Mycobacterium tuberculosis, M. avium and M. kansasii. $^{14}$

The aforementioned Negishi coupling of aryl iodides with oxazole introduced the requisite 2-aryl substituent. A direct arylation at the 5-position with the electron rich aryl iodides 3,4-dimethoxyiodobenzene and 3,4-methylenedioxyiodobenzene afforded balsoxin, 18, and texaline, 19, respectively, in good yield (Scheme 3). The power of the direct arylation approach can be appreciated in comparison to literature preparations of these two natural products. Hodgetts and Kershaw synthesised balsoxin in 7 steps, $40 \%$ overall yield in a Suzuki-Miyaura approach, starting from ethyl 2-amino oxazole carboxylate, ${ }^{15}$ whilst Copp and co-workers synthesised texaline in 6 steps, $4 \%$ overall yield using a condensation approach. $^{16}$

In conclusion, we have developed a mild direct arylation method for the synthesis of 2,5-disubstituted oxazoles and applied it to the two-step assembly of balsoxin and texaline.

We thank Novartis, The EU and the University of Edinburgh for funding. The EPSRC mass spectrometry service at the University of Swansea is acknowledged and Prof. Simon Parsons (School of Chemistry, University of Edinburgh) is thanked for assistance with X-ray crystallography.

\section{Notes and references}

confined to individual substrates and uniformly taking place at elevated temperatures. ${ }^{11}$ Preliminary results suggest that the on water arylation will be effective for the acidic azole 2position; treatment of 5-phenyloxazole with $p$-chloroiodobenzene afforded the 2,5-diaryloxazole product in a good $71 \%$ yield. ${ }^{9}$

Having established the method for the 2-step synthesis of 2,5-diaryloxazoles, we applied the chemistry to the rapid construction of two oxazole natural products. Balsoxin and
1 J. J. Lie and G. W. Gribble, Palladium in Heterocyclic Chemistry, Elsevier, Oxford, 2nd edn, 2007.

2 S. L. Schreiber and M. D. Burke, Angew. Chem., Int. Ed., 2004, 43, 46.

3 Recent reviews: (a) I. V. Seregin and V. Gevorgyan, Chem. Soc. Rev., 2007, 36, 1173; (b) D. Alberico, M. E. Scott and M. Lautens, Chem. Rev., 2007, 107, 174; (c) T. Satoh and M. Miura, Chem. Lett., 2007, 36, 200; (d) L.-C. Campeau and K. Fagnou, Chem. Commun., 2006, 1253. 
4 Recent examples of direct arylation of heteroarenes: (a) I. Čern̆a, R. Pohl and M. Hocek, Chem. Commun., 2007, 4729; (b) D. R. Stuart, E. Villemure and K. Fagnou, J. Am. Chem. Soc., 2007, 129, 12072; (c) K. L. Hull and M. S. Sanford, J. Am. Chem. Soc., 2007, 129, 11904; (d) F. Bellina, S. Cauteruccio and R. Rossi, J. Org. Chem., 2007, 72, 8543; (e) H.-Q. Do and O. Daugulis, J. Am. Chem. Soc., 2007, 129, 12404; (f) A. C. F. Cruz, N. D. Miller and M. C. Willis, Org. Lett., 2007, 9, 4391; $(g)$ P. Amaladass, J. A. Clement and A. K. Mohanakrishnan, Tetrahedron, 2007, 63, 10363; (h) L. Ackermann, R. Born and P. Alvarez-Bercedo, Angew. Chem., Int. Ed., 2007, 46, 6364; (i) T. Niwa, H. Yorimitsu and K. Oshima, Org. Lett., 2007, 9, 2373; (j) S. Chuprakov, N. Chernyak, A. S. Dudnik and V. Gevorgyan, Org. Lett., 2007, 9, 2333; $(k) \mathrm{H}$. A. Chiong and O. Daugulis, Org. Lett., 2007, 9, 1449; (l) Z. Zhang, Z. Hu, Z. Yu, P. Lei, H. Chi, Y. Wang and R. He, Tetrahedron Lett., 2007, 48, 2415; ( $m$ ) X. Wang, D. V. Gribkov and D. Sames, J. Org. Chem., 2007, 72, 1476; (n) J. C. Rech, M. Yato, D. Duckett, B. Ember, P. V. Lo Grasso, R. G. Bergman and J. A. Ellman, J. Am. Chem. Soc., 2007, 129, 490; (o) F. Bellina, C. Calandri, S. Cauteruccio and R. Rossi, Tetrahedron, 2007, 63, 1970; $(p)$ A. Battace, M. Lemhadri, T. Zair, H. Doucet and M. Santelli, Organometallics, 2007, 26, 472; (q) S. Yanagisawa, T. Sudo, R. Noyori and K. Itami, J. Am. Chem. Soc., 2006, 128, 11748; (r) P. Forgione, M. C. Brochu, M. St-Onge, K. H. Thesen, M. D. Bailey and F. Bilodeau, J. Am. Chem. Soc., 2006, 128, 11350; $(s)$ M. Nakano, T. Satoh and M. Miura, J. Org. Chem., 2006, 71, 8309; $(t)$ J. Koubachi, S. El Kazzouli, S. Berteina-Raboin, A. Mouaddib and G. Guillaumet, Synlett, 2006, 3237; (u) I. Cerna, R. Pohl, B. Klepetarova and M. Hocek, Org. Lett., 2006, 8, 5389; (v) K. Mitsudo, P. Thansandote, T. Wilhelm, B. Mariampillai and M. Lautens, Org. Lett., 2006, 8, 3939; (w) C. Blaszykowski, E. Aktoudianakis, C. Bressy, D. Alberico and M. Lautens, Org. Lett., 2006, 8, 2043; (x) J.-P. Leclerc and K. Fagnou, Angew. Chem., Int. Ed., 2006, 45, 7781; (y) J. C. Lewis, J. Y. Wu, R. G. Bergman and J. A. Ellman, Angew. Chem., Int. Ed., 2006, 45, 1589.

5 D. C. Palmer and E. C. Taylor, The Chemistry of Heterocyclic Compounds, vol. 60, Oxazoles: Synthesis, Reactions, and Spectroscopy, Parts A \& B, Wiley, New Jersey, 2004.
6 M. R. Reeder, H. E. Gleaves, S. A. Hoover, H. R. Imbordino and J. J. Pangborn, Org. Process Res. Dev., 2003, 7, 696.

7 S. Narayan, J. Muldoon, M. G. Finn, V. V. Fokin, H. C. Kolb and K. B. Sharpless, Angew. Chem., Int. Ed., 2005, 44, 3275.

8 G. L. Turner, J. A. Morris and M. F. Greaney, Angew. Chem., Int. Ed., 2007, 46, 7996.

9 See Supporting Informationł.

10 (a) A. Mori and K. Masui, Japanese Patent JP 2005220075 A 20050818, 2005; (b) A. Mori and K. Masui, Chem. Abstr., 2005, 143, 211903.

11 (a) Y. Aoyagi, A. Inoue, I. Koizumi, R. Hashimoto, K. Tokunaga, K. Gohma, J. Komatsu, K. Sekine, A. Miyafuji, J. Kunoh, R. Honma, Y. Akita and A. Ohta, Heterocycles, 1992, 33, 257; (b) J. R. Proudfoot, K. D. Hargrave, S. R. Kapadia, U. R. Patel, K. G. Grozinger, D. W. McNeil, E. Cullen, M. Cardozo, L. Tong, T. A. Kelly, J. Rose, E. David, S. C. Mauldin, V. U. Fuchs, J. Vitous, M. Hoermann, J. M. Klunder, P. Raghavan, J. W. Skiles, P. Mui, D. D. Richman, J. L. Sullivan, C.-K. Shih, P. M. Grob and J. Adams, J. Med. Chem., 1995, 38, 4830; (c) S. Pivsa-Art, T. Satoh, Y. Kawamura, M. Miura and M. Nomura, Bull. Chem. Soc. Jpn., 1998, 71, 467; (d) C. Hoarau, A. Du Fou de Kerdaniel, N. Bracq, P. Grandclaudon, A. Couture and F. Marsais, Tetrahedron Lett., 2005, 46, 8573; (e) G.-H. Kuo, A. Wang, S. Emanuel, A. DeAngelis, R. Zhang, P. J. Connolly, W. V. Murray, R. H. Gruninger, J. Sechler, A. Fuentes-Pesquera, D. Johnson, S. A. Middleton, L. Jolliffe and X. Chen, J. Med. Chem., 2005, 48, 1886; $(f)$ F. Bellina, S. Cauteruccio and R. Rossi, Eur. J. Org. Chem., 2006, 1379.

12 B. Burke, H. Parkins and A. M. Talbot, Heterocycles, 1979, 12, 349.

13 X. A. Domínguez, G. de la Fuenta, A. G. González, M. Reina and I. Timón, Heterocycles, 1988, $27,35$.

14 N. Rastogi, J. Abaul, K. S. Goh, A. Devallois, E. Philogène and P. Bourgeois, FEMS Immunol. Med. Microbiol., 1998, 20 267.

15 K. J. Hodgetts and M. T. Kershaw, Org. Lett., 2002, 4, 2905.

16 A. C. Giddens, H. I. M. Boshoff, S. G. Franzblau, C. E. Barry III and B. R. Copp, Tetrahedron Lett., 2005, 7355. 